\title{
MIRADAS Y REFLEXIONES DESDE LA HISTORIA SUDAMERICANA: DESAFÍOS PARA EL PRESENTE
}

\author{
VIEWS AND REFLECTIONS FROM SOUTH AMERICAN HISTORY: \\ CHALLENGES FOR THE PRESENT
}

\author{
Alberto Díaz Araya*, Karelia Cerda Castro**
}

El presente número de Diálogo Andino, Revista de Historia, Geografía y Cultura Andina, inicia con el dossier "Cultura gubernamental y jurídica, actores políticos y redes de poder en el centro sur andino, siglos XVI-XIX", coordinado por Germán Morong y Ana María Presta y que reúne a investigadores e investigadoras tanto de Chile como Argentina, quienes abordan relevantes aspectos de la historia jurídica del sur andino desde distintos enfoques. Luego se presentan dos reseñas del libro "Históricas: movimientos feministas y de mujeres en Chile, 1850-2020", recientemente publicado por LOM Ediciones, las que estuvieron a cargo de las investigadoras Iris Hernández y Ana María Carrasco. Posteriormente se incorporan 13 artículos que analizan, desde distintas disciplinas, temáticas de gran relevancia para el sur andino y Latinoamérica en general.

En primer lugar, Jhon Antón Sánchez presenta una interesante reflexión desde el Derecho respecto de la categoría jurídica de las y los afrodescendientes en América Latina, en el marco de su reconocimiento como sujeto colectivo de derecho promovido por la Corte Interamericana de Derechos Humanos, lo que tiene implicancias y desafíos tanto para cada país del continente como para el Derecho Internacional.

Posteriormente se presentan dos artículos que analizan dinámicas económicas y sociales en el puerto de Arica. Daniel Soto y Diego Yampara se sitúan en las primeras décadas de actividad económica en la ciudad y puerto de Arica, en donde observaron las primeras políticas estatales -específicamente, la ley que otorgó la categoría de Puerto Libre- y el actuar de las élites locales frente a estas. Por su parte, Camila Álvarez y Camilo Santibáñez abordan los conflictos entre distintos actores sociales vinculados a la actividad portuaria en el marco de la privatización del terminal marítimo, lo que adquiere una dimensión específica a partir de la posición transfronteriza del puerto de Arica, acarreando consecuencias políticas, económicas y sociales tanto para Chile como Bolivia.

En el artículo "Diplomacia y migración japonesa en Chile: del proyecto salitrero a la tentativa de colonización en el sur: 1913-1930", los autores proponen una interesante investigación acerca de dos flujos migratorios japoneses, en relación con las actividades económicas de Chile como país receptor, abordando las relaciones diplomáticas con Japón.

Los siguientes dos artículos centran su atención en mujeres indígenas, los que aportan relevantes antecedentes que enriquecen el análisis de la actualidad a partir de un enfoque de género. Brígida Baeza indaga en la reproducción y resignificación de prácticas tradicionales de mujeres quechua en contexto migratorio, específicamente en relación con la salud, en donde se produce un interesante fenómeno de reelaboración y vinculación con otros saberes de pueblos originarios del contexto social en el que se insertan, en este caso la Patagonia argentina. El artículo "Relaciones de mujeres aymara translocales: una explicación desde la presencia/ausencia del Suma Qamaña", indaga en las historias de vida de mujeres aymaras para evidenciar las relaciones que establecen con otredades y con las instituciones, a partir de sus lógicas e identidad indígena.

A continuación se presentan cuatro artículos relacionados con pueblos originarios, desde distintas miradas. José Luis Cabrera entrega una interesante perspectiva de análisis de la libre determinación del pueblo mapuche -temática que atraviesa los

\footnotetext{
* Departamento de Ciencias Históricas y Geográficas, Universidad de Tarapacá. Arica, Chile. Correo electrónico: albertodiaz@academicos.uta.cl

** Departamento de Ciencias Históricas y Geográficas, Universidad de Tarapacá. Arica, Chile. Correo electrónico: kcerdac@academicos.uta.cl
} 
debates actuales, incluyendo las perspectivas futuras ad portas de una nueva Constitución política-, mediante la comparación del impacto territorial tras la imposición del orden colonial y, posteriormente, de las ocupaciones republicanas. Desde un enfoque distinto, Sandra Villanueva aborda los territorios discursivos del pueblo mapuche-williche, para evidenciar la construcción de su propia identidad, al margen de los discursos hegemónicos del Estado chileno. Por otra parte, Melissa Miranda propone un análisis del territorio de Caspana desde la percepción de los pueblos originarios, a partir del concepto de paisaje en movimiento, lo que posibilitó la identificación de lugares significativos para la comunidad, relevando su participación en los mecanismos de gestión patrimonial. Por último, el artículo de Jesús Huanca y Néstor Pilco examina la Independencia de Perú en el escenario puneño, exponiendo como resultados de investigación los impactos sociales, políticos y económicos de dicho proceso sobre la población indígena, considerando el contexto geográfico como último baluarte realista.

Posteriormente, Paula Núñez presenta una revisión de la historia de la Patagonia argentina y una propuesta de marco teórico para su estudio, basado en el cruce entre los elementos sociales y la naturaleza, a partir de la historia ambiental. Edwin Pino indaga en los conflictos sociales que se han generado por el acceso a recursos hídricos, principalmente entre las comunidades y las instituciones, en un territorio caracterizado por la escasez de agua y en donde su disponibilidad resulta estratégica. Finalmente, Romina Grana y M. Laura López, describen las transformaciones de la producción y prácticas culinarias en Guayascate durante la Colonia, en donde proponen que se produjo una mixtura entre las tradiciones locales y los elementos hispanos, con ello evidencian un aspecto interesante del proceso de mestizaje en relación con la cultura. 